Article

\title{
Adsorption of Gold(I) and Gold(III) Using Multiwalled Carbon Nanotubes
}

\author{
Francisco Jose Alguacil 1 \\ Centro Nacional de Investigaciones Metalurgicas (CSIC), Avda. Gregorio del Amo 8, 28040 Madrid, Spain; \\ fjalgua@cenim.csic.es
}

Received: 25 September 2018; Accepted: 10 October 2018; Published: 16 November 2018

check for updates

\section{Featured Application: Recovery of gold from secondary wastes.}

\begin{abstract}
Carbon nanotubes are materials that have been investigated for diverse applications including the adsorption of metals. However, scarce literature has described their behavior in the case of the adsorption of precious metals. Thus, this work reports the efficient adsorption of gold from cyanide or chloride media on multiwalled carbon nanotubes (MWCNTs). In a cyanide medium, gold was adsorbed from alkaline $\mathrm{pH}$ values decreasing the adsorption as the $\mathrm{pH}$ values were increased to more acidic values. In a chloride medium, the MWCNTs were able to load the precious metal and an increased $\mathrm{HCl}$ concentration (0.1-10 M), in the aqueous solution, had no effect on the gold uptake onto the nanotubes. From both aqueous media, the metal adsorption was well represented by the pseudo-second order kinetic model. In the cyanide medium, the film-diffusion controlled process best fitted the rate law governing the adsorption of gold onto the nanotubes, whereas in the chloride medium, the adsorption of the metal onto the nanotubes is best represented, both at $20^{\circ} \mathrm{C}$ and $60^{\circ} \mathrm{C}$, by the particle-diffusion controlled process. With respect to the elution step, in cyanide medium gold loaded onto the nanotubes can be eluted with acidic thiourea solutions, whereas in the chloride medium, and due to that the adsorption process involved the precipitation of zero valent gold onto the multiwalled carbon nanotubes, the elution has been considered as a leaching step with aqua regia. From the eluates, dissolved gold can be conveniently precipitated as zero valent gold nanoparticles.
\end{abstract}

Keywords: multiwalled carbon nanotubes; gold(I); gold(III); adsorption; elution; gold nanoparticles

\section{Introduction}

Nearly 25 years ago, Iijima began considering carbon nanotubes [1]. After this time, scientists began finding applications (including but not excluding: medicine, drug delivery, solar cells, electronics) for carbon nanotubes technologies in different configurations (single and multi-walled carbon nanotubes, functionalized carbon nanotubes) and for different purposes due to their properties including mechanical strength, aspect ratio and electrical and thermal conductivity. As recent literature has indicated, these nanomaterials are unconditionally considered as suitable adsorbents in the treatment of waters and in the recovery and separation of metal species from aqueous solutions [2-12]

Referring to gold adsorption, little information is available using this nanotechnology, despite the fact of the importance and price (reaching USD1244 per ounce barrier as at 16th July 2018) of this metal and its presence in aqueous solutions coming from the processing of ores (alkaline cyanide medium) or jewelry scraps and printed circuit boards (PCBs) (acidic chloride medium). The reference [13] mentioned in the manuscript title about "prerequisites of carbon nanotubes to adsorb gold(III)", though then in the text and conclusions not special mention to such requisites were given, the second 
reference on the topic is about the adsorption of $\mathrm{Cr}(\mathrm{VI})$ and $\mathrm{Au}(\mathrm{III})$ onto oxidized multiwalled carbon nanotubes [14].

Due to this lack of recent information, in the present investigation, the adsorption of gold from these two aqueous media (alkaline cyanide or acidic chloride) by multi-walled carbon nanotubes was considered. The aim was to optimize various operational parameters and, thus, obtain efficient carbon nanotubes processing.

\section{Experimental}

\subsection{Reagents and Solutions}

The multi-walled carbon nanotubes were obtained from Fluka and their main characteristics are summarized in Table 1. Further characterization of the carbon nanotubes, including zero potential and Micro-Raman spectra are described elsewhere [15]. Other chemicals used were AR (analytical reagent) grade, except the complex $\mathrm{KCu}(\mathrm{CN})_{4}$, which was prepared according to the literature [16]. Gold cyanide solutions were prepared by dissolving $\mathrm{KAu}(\mathrm{CN})_{2}$ in distilled water. The different concentrations used in the experiments were prepared from a stock solution of $0.1 \mathrm{~g} / \mathrm{L}$ gold(I). The $\mathrm{pH}$ of the solution was adjusted by the addition of hydrochloric acid or sodium hydroxide solutions. During the experiments, the $\mathrm{pH}$ was continuously controlled using a $605 \mathrm{pH}$-meter (2000, Crison, Madrid, Spain). In acidic chloride media, the gold(III) solutions were prepared in a similar manner using $\mathrm{HAuCl}_{4}$.

Table 1. Characteristics of the multi-walled carbon nanotubes.

\begin{tabular}{cc}
\hline Type & Multi-Walled \\
\hline melting range & $3652-3697^{\circ} \mathrm{C}$ \\
density & $2.1 \mathrm{~g} \mathrm{~mL}^{-1}$ \\
appearance & dust \\
purity & $\geq 98 \%$ carbon basis \\
dimensions & $10 \pm 1 \mathrm{~nm}$ external diameter \\
& $4.5 \pm 0.5 \mathrm{~nm}$ internal diameter \\
maximum adsorption & $3-6 \mu \mathrm{m}(\text { length })^{-1}$ \\
BET & $1295 \mathrm{~cm}^{3} \mathrm{~g}^{-1}$ \\
\end{tabular}

\subsection{Gold Adsorption Measurements}

The adsorption experiments were carried out using a glass reactor with mechanical $(27 \mathrm{~mm}$ diameter four blades impeller) stirring. The desired gold solution $(100 \mathrm{~mL})$ was put into the reactor and to this the corresponding amount of the multi-walled carbon nanotubes was added. The elution experiments were carried out in a similar device, putting together the gold-loaded carbon nanotubes and the elution phase.

Gold or metal concentrations in the aqueous solution were analyzed by atomic absorption spectrometry, using a Perkin Elmer 1100B spectrophotometer (wavelength 242.8 nm, 1993, Perkin Elmer, Oxford, UK). The percentage of metal adsorption was calculated by the difference between the initial metal concentration and the corresponding one encountered in the solution at elapsed times.

SEM and Energy Dispersive X-ray Spectrodcopy (EDS) analyses were carried out in a Hitachi S-4800 equipment (2009, Hitachi, Osaka, Japan).

\section{Results and Discussion}

\subsection{Carbon Nanotubes Characterization}

As it is mentioned in Section 2.1, the characterization of the carbonaceous material used in the present work was described elsewhere [15], though for the benefit of the readers of the present work 
some data were included here. This material presented an isoelectric point of 3.6, whereas Raman data are summarized in Table 2.

Table 2. Raman data of the multiwalled carbon nanotubes.

\begin{tabular}{cccccc}
\hline & D & G & D $^{\prime}$ & 2D & G+D \\
\hline Raman shift & 1339 & 1573 & 1607 & 2675 & 2913 \\
Area signal & 102.4 & 76.2 & 6.8 & 90.1 & 106.8 \\
\hline
\end{tabular}

The $\mathrm{I}_{\mathrm{D}}: \mathrm{I}_{\mathrm{G}}$ value obtained for these multiwalled carbon nanotubes is 1.34 , indicating the presence of little defects in their structure.

\subsection{Gold Adsorption from Cyanide Media}

The literature remarks that the gold(I) cyanide complex is adsorbed predominantly onto activated carbon as an ion pair [17], thus similarly, at neutral-alkaline $\mathrm{pH}$ values, the adsorption of gold(I) cyanide by the carbon nanotubes may be broadly represented by the general equilibrium:

$$
\mathrm{M}_{\mathrm{aq}}^{+}+\mathrm{nAu}(\mathrm{CN})_{2}^{-} \mathrm{aq} \Leftrightarrow \mathrm{M}^{+}\left[\mathrm{Au}(\mathrm{CN})_{2}^{-}\right]_{\mathrm{NTb}}
$$

which is, as is demonstrated below, $\mathrm{pH}$-dependent; aq and NTb denote species in the aqueous and carbon phases, respectively, and $\mathrm{M}$ being the accompanying metal.

\subsubsection{Influence of Stirring Speed of the Aqueous Phase}

In all of the adsorption experiments, a stirring speed of $600 \mathrm{~min}^{-1}$ was used for the aqueous phases. Previous experiments, carried out with an aqueous phase containing $0.01 \mathrm{~g} \mathrm{~L}^{-1} \operatorname{gold}(\mathrm{I})$ at $\mathrm{pH}$ $8 \pm 0.1$, and a carbon nanotube dosage of $1 \mathrm{~g} \mathrm{~L}^{-1}$, showed that the maximum percentage of gold(I) removal becomes virtually independent ( $40 \%$ after $2 \mathrm{~h}$ ) of the stirring speed in the $500-1000 \mathrm{~min}^{-1}$ range, which also indicates that a minimum value of the thickness of the aqueous phase boundary layer is reached. Thus, a stirring speed of $600 \mathrm{~min}^{-1}$ was used in subsequent experiments.

\subsubsection{Effect of Aqueous $\mathrm{pH}$ Value}

Figure 1 shows the results obtained for the adsorption of $\mathrm{Au}(\mathrm{CN})_{2}{ }^{-}$at various aqueous $\mathrm{pH}$ values. The carbon nanotubes dosage used in the experiments was of $2 \mathrm{~g} \mathrm{~L}^{-1}$. The aqueous phase contained $0.01 \mathrm{~g} \mathrm{~L}^{-1}$ of gold(I) at various $\mathrm{pH}$ values. The results shown in Figure 1 demonstrate that the variation of the aqueous $\mathrm{pH}$ value increases the removal of gold when these $\mathrm{pH}$ values are shifted towards more acidic values. It should be noted here that the gold(I)-cyanide complex is stable even at acidic $\mathrm{pH}$ values and only decomposes at these low $\mathrm{pH}$ values after a long time (several hours) to yield a yellow AuCN solid. The experimental values obtained at $\mathrm{pH} 13$ were used to estimate the rate law in the adsorption of gold(I) by these multiwalled carbon nanotubes, experimental data best fitted to the film-diffusion controlled mechanism $\left(\mathrm{r}^{2}: 0.9542\right)$ :

$$
\ln (1-\mathrm{F})=-\mathrm{kt}
$$

where $\mathrm{F}$ is the factorial approach to the equilibrium, defined as:

$$
\mathrm{F}=\frac{[\mathrm{Au}]_{\mathrm{nt,t}}}{[\mathrm{Au}]_{\mathrm{nt}, \mathrm{e}}}
$$

where $[\mathrm{Au}]_{n t, t}$ and $[\mathrm{Au}]_{n t, e}$ are the gold concentration in the nanotubes at an elapsed time $t$ and at equilibrium, respectively, and $\mathrm{k}$ is the rate constant $\left(0.59 \mathrm{~min}^{-1}\right)$. 


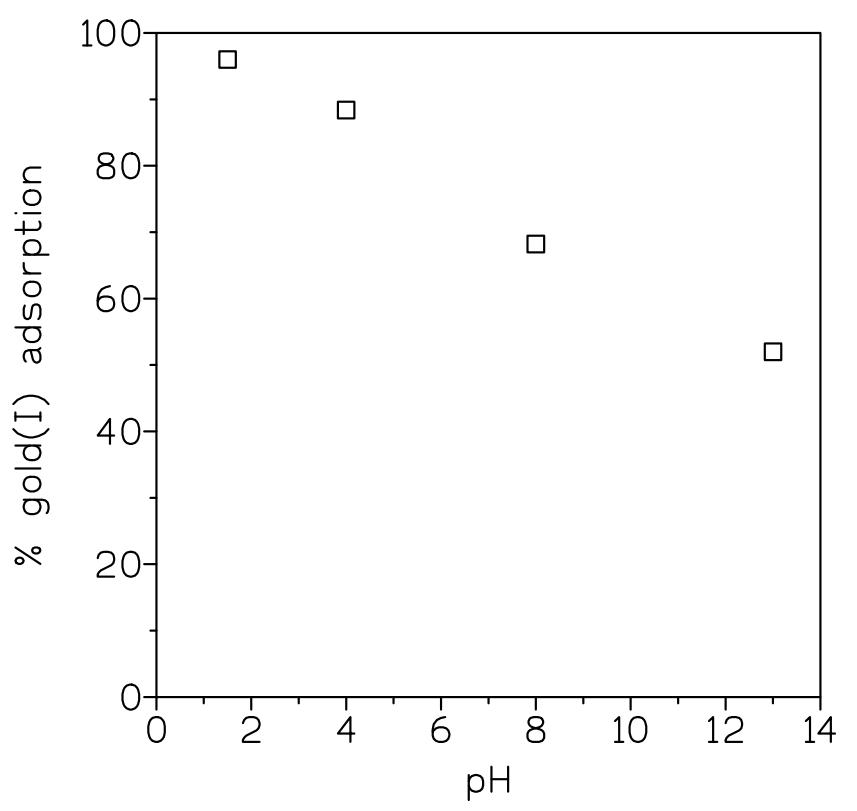

Figure 1. Effect of the $\mathrm{pH}$ variation on gold(I) adsorption. Time: $2 \mathrm{~h}$.

\subsubsection{Effect of Temperature}

Aqueous solutions containing $0.01 \mathrm{~g} \mathrm{~L}^{-1} \operatorname{gold}(\mathrm{I})$ at $\mathrm{pH} 13 \pm 0.1$ were used to investigate the effect of this variable on gold(I) adsorption. The adsorbent dosage was $2 \mathrm{~g} \mathrm{~L}^{-1}$ and the temperature was varied from 20 to $60^{\circ} \mathrm{C}$. From the results presented in Table 3, it can be shown that the increase in the temperature leads to a decrease in metal adsorption. From the $\mathrm{D}$ (distribution coefficient) value, defined as:

$$
\mathrm{D}=\frac{[\mathrm{Au}]_{\mathrm{nt}, \mathrm{e}}}{[\mathrm{Au}]_{\mathrm{s}, \mathrm{e}}}
$$

and plotting $\log \mathrm{D}$ versus $1 / \mathrm{T}$, the slope indicated that the adsorption reaction has an exothermic character $\left(\Delta \mathrm{H}^{\circ}=-13 \mathrm{~kJ} \mathrm{~mol}^{-1}\right)$ and the intercept that $\Delta \mathrm{S}^{\circ}$ is $-50 \mathrm{~J} \mathrm{~mol}^{-1} \mathrm{~K}^{-1}$. In the above reaction, $[\mathrm{Au}]_{n t, \mathrm{e}}$ and $[\mathrm{Au}]_{s, \mathrm{e}}$ are the gold equilibrium concentrations in the nanotubes and in the solution, respectively. From the values of the enthalpy and the entropy values, the value of $\Delta \mathrm{G}^{\circ}$ was calculated as $-28 \mathrm{~kJ} \mathrm{~mol}^{-1}$. The negative energy value indicated a spontaneous adsorption, whereas the negative entropy change is an indication of a decreased randomness at the solid/liquid interface during the adsorption process.

Table 3. Effect of temperature on gold(I) adsorption.

\begin{tabular}{cc}
\hline Temperature, ${ }^{\circ} \mathbf{C}$ & \% Gold Adsorption \\
\hline 20 & 52.5 \\
40 & 44.0 \\
60 & 36.5 \\
\hline
\end{tabular}

\subsubsection{Effect of the Aqueous Phase/Adsorbent Relationship on Gold Removal}

In Table 4, the gold percentage of adsorption, at different aqueous phase/adsorbent relationships, is given in order to study the effect of this variation on gold(I) adsorption. Experiments were carried out at a constant $\mathrm{pH}$ value of $13 \pm 0.1$. Aqueous phases contained $0.01 \mathrm{~g} \mathrm{~L}^{-1} \operatorname{gold}(\mathrm{I})$. The results obtained reveal an important change in the metal adsorption at lower aqueous phase/adsorbent relationships, since this adsorption is in the $90 \%$ range when the lowest relationships are used against 
recoveries of about $30 \%$, obtained when the above relationship is 4000 . In this same Table, the metal uptake is also given, showing the increase of this value as the ratio liquid/solid is increased.

Table 4. Influence of the liquid/solid relationship on gold(I) adsorption.

\begin{tabular}{ccc}
\hline L/S Relationship & \% Gold Adsorption $^{\mathbf{a}}$ & ${\text { Gold Uptake, } \mathbf{~ m ~}^{\mathbf{- 1}} \mathbf{a}}^{\text {(1) }}$ \\
\hline 125 & 93.0 & 1.2 \\
250 & 90.0 & 2.3 \\
500 & 57.0 & 2.9 \\
1000 & 50.0 & 5.0 \\
2000 & 40.5 & 8.2 \\
4000 & 31.5 & 12.8 \\
\hline
\end{tabular}

The values in Table 4 were used to estimate the loading isotherm, the fit of the experimental data responded best to the Langmuir isotherm but with a discrete $r^{2}$ value of 0.8338 .

\subsubsection{Separation of Gold (I) from Metal-Cyanide Complexes}

In order to investigate the effect of other metal-cyanide complexes accompanying $\mathrm{Au}(\mathrm{CN})_{2}{ }^{-}$, a study was carried out about their interference with the overall transport of gold(I). The metal-cyanide complexes studied, $\mathrm{Cu}(\mathrm{CN})_{4}{ }^{3-}, \mathrm{Fe}(\mathrm{CN})_{6}{ }^{3-}$ and $\mathrm{Fe}(\mathrm{CN})_{6}{ }^{4-}$, were investigated in the form of binary mixtures with $\mathrm{Au}(\mathrm{CN})_{2}$ - on a 1:1 molar basis. Thus, the feed phase contained $5.1 \times 10^{-5} \mathrm{M}$ of each metal in aqueous solutions of $\mathrm{pH} 13 \pm 0.1$ and the carbon dosage was of $2 \mathrm{~g} \mathrm{~L}^{-1}$.

The results obtained indicated very low $\mathrm{Cu}(\mathrm{I}), \mathrm{Fe}(\mathrm{II})$ and $\mathrm{Fe}(\mathrm{III})$ adsorption. From the D values defined as in Equation (4), the values of the separation factors $\mathrm{Au}(\mathrm{I}) / \mathrm{M}$, defined as

$$
\beta_{\frac{\mathrm{Au}}{\mathrm{M}}}=\frac{\mathrm{D}_{\mathrm{Au}}}{\mathrm{D}_{\mathrm{M}}},
$$

are summarized in Table 5 and show the excellent possibilities, $\beta$ values greater than 1 , of these nanomaterials to separate gold(I) from these others accompanying metals in the solution.

Table 5. Adsorption of different metal-cyano complexes and selectivity of the system.

\begin{tabular}{|c|c|c|c|c|c|}
\hline Metal Pair & Complex & {$[\mathrm{M}], \mathrm{mg} \mathrm{g}^{-1}$} & {$[\mathrm{M}], \mathrm{mg} \mathrm{L}^{-1}$} & $\mathrm{D}, \mathrm{L} \mathrm{g}^{-1}$ & $\beta_{\mathrm{Au}(\mathrm{I}) / \mathrm{M}}$ \\
\hline $\mathrm{Au}(\mathrm{I})$ & $\mathrm{Au}(\mathrm{CN})_{2}^{-}$ & 2.8 & 4.4 & 0.64 & \multirow[b]{2}{*}{64} \\
\hline $\mathrm{Cu}(\mathrm{I})$ & $\mathrm{Cu}(\mathrm{CN})_{4}{ }^{3-}$ & 0.03 & 3.2 & 0.01 & \\
\hline $\mathrm{Au}(\mathrm{I})$ & $\mathrm{Au}(\mathrm{CN})_{2}^{-}$ & 3.1 & 3.9 & 0.79 & \multirow{2}{*}{7.2} \\
\hline $\mathrm{Fe}(\mathrm{II})$ & $\mathrm{Fe}(\mathrm{CN})_{6}^{4-}$ & 0.25 & 2.3 & 0.11 & \\
\hline $\mathrm{Au}(\mathrm{I})$ & $\mathrm{Au}(\mathrm{CN})_{2}^{-}$ & 3.3 & 3.5 & 0.94 & \multirow{2}{*}{7.2} \\
\hline $\mathrm{Fe}(\mathrm{III})$ & $\mathrm{Fe}(\mathrm{CN})_{6}^{3-}$ & 0.29 & 2.2 & 0.13 & \\
\hline
\end{tabular}

Time: $2 \mathrm{~h}$.

\subsection{Gold Adsorption from Chloride Media}

The adsorption of $\mathrm{Au}(\mathrm{III})$ from $\mathrm{HCl}$ solutions by the multi-walled carbon nanotubes was also investigated. The adsorption equilibrium can be firstly described by the next general reaction:

$$
\mathrm{AuCl}_{4}^{-} \text {aq } \Leftrightarrow \mathrm{AuCl}_{4}^{-} \mathrm{NTb}
$$

where aq and Ntb represent the aqueous and solid phases, respectively. However, there is evidence of reduction of gold(III) to metallic gold, as the SEM image shows (Figure 2). As it is observed from this figure, dark particles appeared on the gold-loaded carbon nanotubes. These particles are of metallic 
gold as the EDS spectrum (Figure 3) showed two peaks at $9.7 \mathrm{keV}(\mathrm{L} \alpha)$ and $2.1 \mathrm{keV}(\mathrm{M} \alpha)$ characteristic of metallic gold. Very probably this reduction occurs on the carbon surface [17], being the reactions involved in the metal reduction:

$$
\mathrm{AuCl}_{4}^{-}+3 \mathrm{e}^{-} \Leftrightarrow \mathrm{Au}^{0}+4 \mathrm{Cl}^{-}, E^{0}=1.00 \mathrm{~V}
$$

if the gold(III) reduces directly to metallic gold, or:

$$
\begin{gathered}
\mathrm{AuCl}_{4}^{-}+2 \mathrm{e}^{-} \Leftrightarrow \mathrm{AuCl}_{2}^{-}+2 \mathrm{Cl}^{-}, E^{0}=0.92 \mathrm{~V} \\
\mathrm{AuCl}_{2}^{-}+\mathrm{e}^{-} \Leftrightarrow \mathrm{Au}^{0}+2 \mathrm{Cl}^{-}, E^{0}=1.16 \mathrm{~V}
\end{gathered}
$$

if the reduction occurs via the formation of the $\mathrm{AuCl}_{2}{ }^{-}$intermediate. In any case, the source for the electrons is the carbon nanotube:

$$
\mathrm{C}+2 \mathrm{H}_{2} \mathrm{O} \Leftrightarrow 4 \mathrm{H}^{+}+\mathrm{CO}_{2}+4 \mathrm{e}^{-}, E^{0}=0.21 \mathrm{~V}
$$

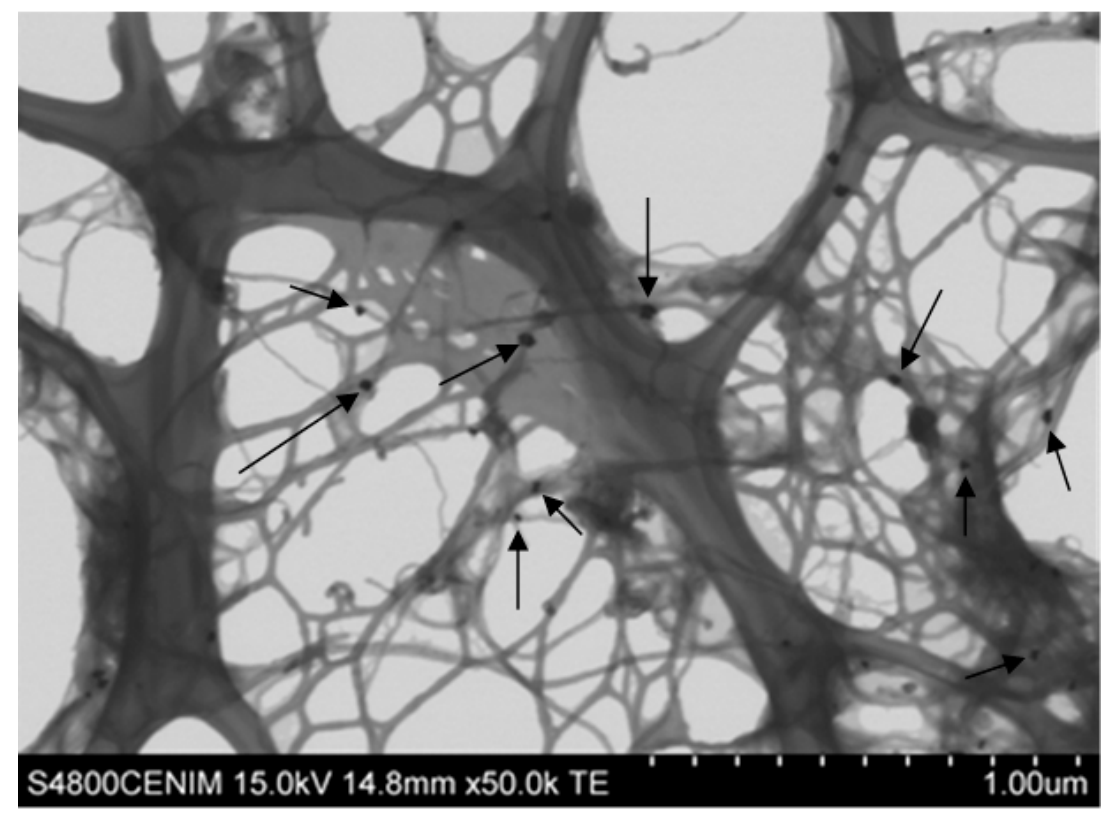

Figure 2. SEM image of gold-loaded multi-walled carbon nanotubes. Arrows pointing to zero valent gold particles.

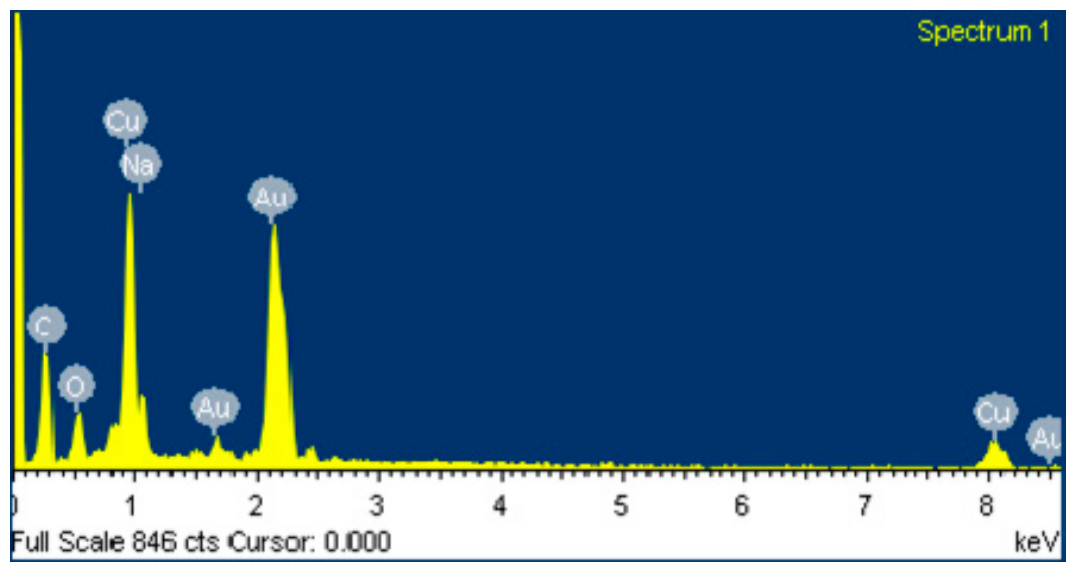

Figure 3. Energy Dispersive X-ray Spectroscopy spectrum of the dark particles (zero valent gold) of Figure 2. 


\subsubsection{Influence of the Stirring Speed in the Aqueous Phase}

Experiments were performed to establish adequate hydrodynamic conditions. The adsorption of gold(III) was studied as a function of the stirring speed on the aqueous phase solution side and the results obtained are shown in Figure 4. Near constant adsorption for stirring speeds in the $500-750 \mathrm{~min}^{-1}$ range was obtained. Consequently, the thickness of the aqueous diffusion layer and the aqueous resistance to mass transfer were minimized. The diffusion contribution of the aqueous species to the mass transfer process was assumed to be constant. A stirring speed of $500 \mathrm{~min}^{-1}$ was maintained throughout all the investigation for the aqueous phase. The decrease of the percentage of gold(III) adsorption at stirring speeds above $750 \mathrm{~min}^{-1}$ is attributable to excessive speed resulting in local gold(III)-carbon nanotubes equilibrium, thus, decreasing the value of the percentage of the removal of this precious metal from the aqueous solution.

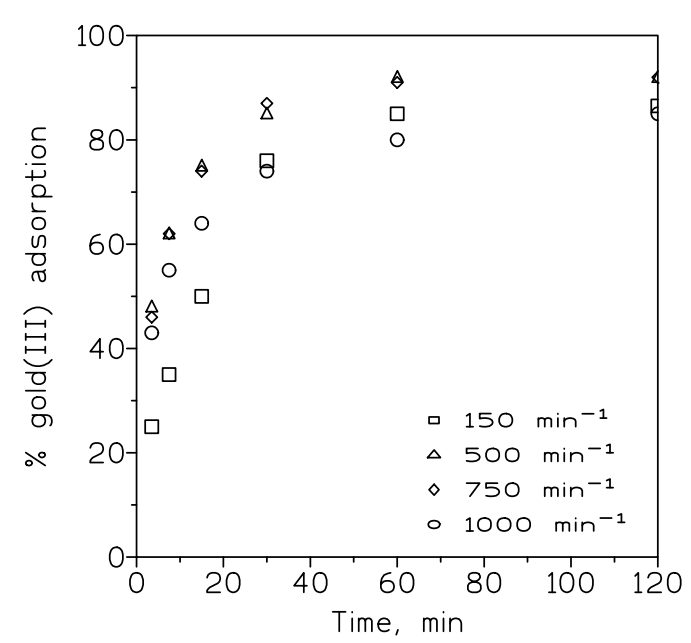

Figure 4. Influence of the stirring speed on gold(III) adsorption. Aqueous solution: $0.005 \mathrm{~g} \mathrm{~L}^{-1} \mathrm{Au}(\mathrm{III})$ in $0.1 \mathrm{M} \mathrm{HCl}$. Adsorbent dosage: $0.25 \mathrm{~g} \mathrm{~L}^{-1}$. Time: $2 \mathrm{~h}$.

\subsubsection{Influence of Temperature}

Experiments were performed to investigate the effect of this variable on gold(III) adsorption with an aqueous solution containing $0.005 \mathrm{~g} \mathrm{~L}^{-1}$ gold(III) at $0.1 \mathrm{M} \mathrm{HCl}$ and a carbon nanotubes dosage of $0.25 \mathrm{~g} \mathrm{~L}^{-1}$. From the results obtained, it is shown that the increase of the temperature from 20 to $60^{\circ} \mathrm{C}$ had no effect on gold adsorption, reaching $92 \%$ after $30 \mathrm{~min}$, in any case. However, the time to reach this maximum adsorption is temperature dependent (Figure 5).

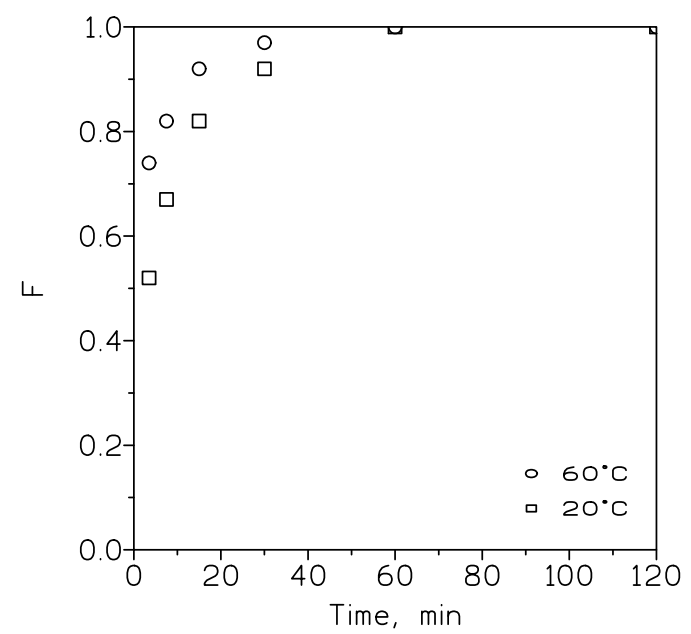

Figure 5. Influence of temperature on gold(III) adsorption. The F values were calculated as in Equation (3). 


\subsubsection{Influence of the Carbon Nanotubes Dosage}

A series of experiments were performed using aqueous solutions containing $0.005 \mathrm{~g} \mathrm{~L}^{-1}$ gold(III) and $0.1 \mathrm{M} \mathrm{HCl}$, whereas the carbon nanotubes dosage was varied from 0.05 to $0.5 \mathrm{~g} \mathrm{~L}^{-1}$, in order to investigate the influence of this variation on gold(III) adsorption. Table 6 shows the variation of the percentage of gold adsorption and metal loading for different carbon nanotubes dosages. This shows that the increase of the amount of carbon nanotubes added to the solution increased the percentage of metal adsorbed onto the nanotubes.

Table 6. Influence of nanotubes dosage on gold(III) adsorption.

\begin{tabular}{|c|c|c|}
\hline Dosage, $\mathrm{g} \mathrm{L}^{-1}$ & \% Gold Adsorption & Metal Uptake, $\mathrm{mg} \mathrm{g}^{-1 \mathrm{a}}$ \\
\hline 0.5 & 99.5 & 10.0 \\
\hline 0.25 & 92.0 & 18.4 \\
\hline 0.13 & 51.0 & 19.6 \\
\hline 0.05 & 31.0 & 25.8 \\
\hline
\end{tabular}

\subsubsection{Influence of the Initial Hydrochloric Acid Concentration}

The variation in adsorption, as a function of the initial acid concentration, at $1 \mathrm{~g} \mathrm{~L}^{-1}$ carbon nanotubes dosage, has been studied when the aqueous phase contained $0.005 \mathrm{~g} \mathrm{~L}^{-1}$ gold at different $\mathrm{HCl}$ concentrations. The results are shown in Table 7 , in which a near quantitative gold adsorption occurs at every initial $\mathrm{HCl}$ concentration and $2 \mathrm{~h}$ of contact between the aqueous solution and the adsorbent; though at shorter contact times, i.e., $30 \mathrm{~min}$, an order in the sequence $0.1 \mathrm{M}>1 \mathrm{M}>10 \mathrm{M}$ $\mathrm{HCl}$ was obtained and this is probably due to the existence of the $\mathrm{HAuCl}_{4}$ species in the aqueous phase at higher $\mathrm{HCl}$ concentrations, against the presence of $\mathrm{AuCl}_{4}{ }^{-}$species, at the more dilute hydrochloric acid solutions, which is more readily adsorbed than the former.

Table 7. Influence of initial $\mathrm{HCl}$ concentration on gold(III) adsorption.

\begin{tabular}{ccc}
\hline $\mathbf{H C l}, \mathbf{M}$ & \% After $\mathbf{3 0} \mathbf{~ m i n}$ & \% After $\mathbf{2 ~ h}$ \\
\hline 0.1 & 99.5 & 99.5 \\
1 & 94.0 & 99.5 \\
10 & 66.5 & 99.5 \\
\hline
\end{tabular}

\subsubsection{Influence of the Adsorbent/Aqueous Phase Relationship on the Adsorption of Gold}

The results concerning the adsorption of gold(III) from an aqueous phase containing $0.005 \mathrm{~g} \mathrm{~L}^{-1}$ $\mathrm{Au}(\mathrm{III})$ in $0.1 \mathrm{M} \mathrm{HCl}$, at different volume of solution/carbon nanotubes weight ratios, revealed a change in the percentage of gold adsorption $(92 \%$ at $1 \mathrm{~h}$ of contact) at the lowest solution/adsorbent relationship (4000) against the value of $51 \%$, also at $1 \mathrm{~h}$, obtained for a relationship of 8000 . The gold uptakes were of $18.4 \mathrm{mg} \mathrm{g}^{-1}$ and $20.4 \mathrm{mg} \mathrm{g}^{-1}$ for the low and high ratios, respectively.

\subsubsection{Separation of Gold (III) from Selected Base Metals}

Since base metals are normally found in the gold- $\mathrm{HCl}$ bearing solutions, the selectivity of the present adsorption system against the presence of various metals in the aqueous phase was investigated by using an adsorbent dosage of $0.25 \mathrm{~g} \mathrm{~L}^{-1}$ and the aqueous phase containing $5.1 \times 10^{-5} \mathrm{M} \mathrm{Au}(\mathrm{III})$, $\mathrm{Fe}(\mathrm{III}), \mathrm{Cu}(\mathrm{II})$ in $0.1 \mathrm{M} \mathrm{HCl}$ media. From the results obtained on the basis of binary solutions $\mathrm{Au}(\mathrm{III})$-metal (Table 8), it is inferred that gold was preferably adsorbed over these base metals. The selectivity with respect to gold seems to be enough to separate this precious metal selectively from the base metals. 
Table 8. Adsorption of gold(III) and base metals from acidic medium and separation factors.

\begin{tabular}{|c|c|c|c|c|c|}
\hline Metal Pair & ${ }^{a}$ Chloride Complexes & {$[\mathrm{M}], \mathrm{mg} \mathrm{g}^{-1}$} & {$[\mathrm{M}], \mathrm{mg} \mathrm{L}^{-1}$} & $\mathrm{D}, \mathrm{L} \mathrm{g}^{-1}$ & $\beta_{\mathrm{Au}(\mathrm{III}) / \mathrm{M}}$ \\
\hline $\mathrm{Au}(\mathrm{III})$ & $\mathrm{AuCl}_{4}^{-}$ & 28.8 & 2.8 & 10.3 & \multirow[b]{2}{*}{103} \\
\hline $\mathrm{Ni}(\mathrm{II})$ & $\mathrm{NiCl}^{+}$ & 0.23 & 2.9 & 0.1 & \\
\hline $\mathrm{Au}(\mathrm{III})$ & $\mathrm{AuCl}_{4}^{-}$ & 24.8 & 3.8 & 6.5 & \multirow{2}{*}{81} \\
\hline $\mathrm{Fe}(\mathrm{III})$ & $\mathrm{FeCl}_{2}{ }^{+}, \mathrm{FeCl}^{2+}$ & 0.22 & 2.7 & 0.08 & \\
\hline $\mathrm{Au}(\mathrm{III})$ & $\mathrm{AuCl}_{4}^{-}$ & 27.6 & 2.9 & 9.5 & \multirow{2}{*}{119} \\
\hline $\mathrm{Cu}(\mathrm{II})$ & $\mathrm{CuCl}^{+}$ & 0.26 & 3.1 & 0.08 & \\
\hline
\end{tabular}

${ }^{\mathrm{a}} \mathrm{At} \mathrm{pH} 1$ and $\mathrm{HCl} 0.1 \mathrm{M}$. The values of $\mathrm{D}$ and $\beta$ calculated as in Equations (4) and (5), respectively.

\subsection{Adsorption Kinetics}

To investigate the adsorption rate of both gold(I) and gold(III) onto the carbon nanotubes, the pseudo-first and pseudo-second order rate equations were used to fit the experimental data. The calculations concluded that the pseudo-second order model [18],

$$
\frac{\mathrm{t}}{[\mathrm{Au}]_{\mathrm{r}, \mathrm{t}}}=\frac{1}{\mathrm{k}_{2}[\mathrm{Au}]_{\mathrm{r}, \mathrm{e}}^{2}}+\frac{\mathrm{t}}{[\mathrm{Au}]_{\mathrm{r}, \mathrm{e}}}
$$

best fits to the experimental data both for the $\mathrm{Au}(\mathrm{I})$ and $\mathrm{Au}(\mathrm{III})$ systems. In this equation, $\mathrm{k}_{2}$ is the rate constant, and $[\mathrm{Au}]_{\mathrm{r}, \mathrm{t}}$ and $[\mathrm{Au}]_{\mathrm{r}, \mathrm{e}}$ are the gold concentrations in the nanotubes at an elapsed time $t$ and at equilibrium, respectively. Thus, the rate constants were estimated as $0.72 \mathrm{~g} \mathrm{mg}^{-1} \mathrm{~min}^{-1}\left(\mathrm{r}^{2}=1.000\right)$ for gold(I) and $0.014 \mathrm{~g} \mathrm{mg}^{-1} \mathrm{~min}^{-1}\left(\mathrm{r}^{2}=0.9997\right)$ for gold(III). These data suggest that chemical adsorption also contributes to physical adsorption to the overall metal adsorption onto the multi-walled carbon nanotubes [19].

\subsection{Elution}

After the adsorption of the metal onto the adsorbents, the next step should be the recovery of the metal from the adsorbent for a final recovery or dumping step. This desorption step, also called the elution step, is of equal importance as the adsorption step [20], though it is sometimes neglected by authors in their publications, i.e., References $[2,7,12,21,22]$.

In the present investigation and in the case of gold(I), besides the methods described in the literature for gold desorption or elution from gold-loaded activated carbon [17], the elution of this element from the loaded carbon nanotubes can be accomplished using acidic thiourea solutions $\left(1 \mathrm{~g} \mathrm{~L}^{-1}\right.$ thiourea in $0.1 \mathrm{M} \mathrm{HCl}$ ), reaching yields of near $65 \%$ of gold recovery (batch experiments at $20^{\circ} \mathrm{C}$ and a volume of eluant/weight of gold-loaded carbon nanotubes relationship of 200) after 15 min of contact of the gold-loaded nanotubes and the eluant.

In the case of gold(III) and due to the presence of metallic gold in the nanotubes, the elution step may be considered as a dissolution problem rather than a true elution step. Thus in this case, the removal of gold from the nanotubes may be accomplished by the use of aqua regia, which dissolves the gold particles and renders a concentrated and pure gold solution from which gold can be recovered as gold nanoparticles (Figure 6), accordingly with the procedure described in the literature [23]. 


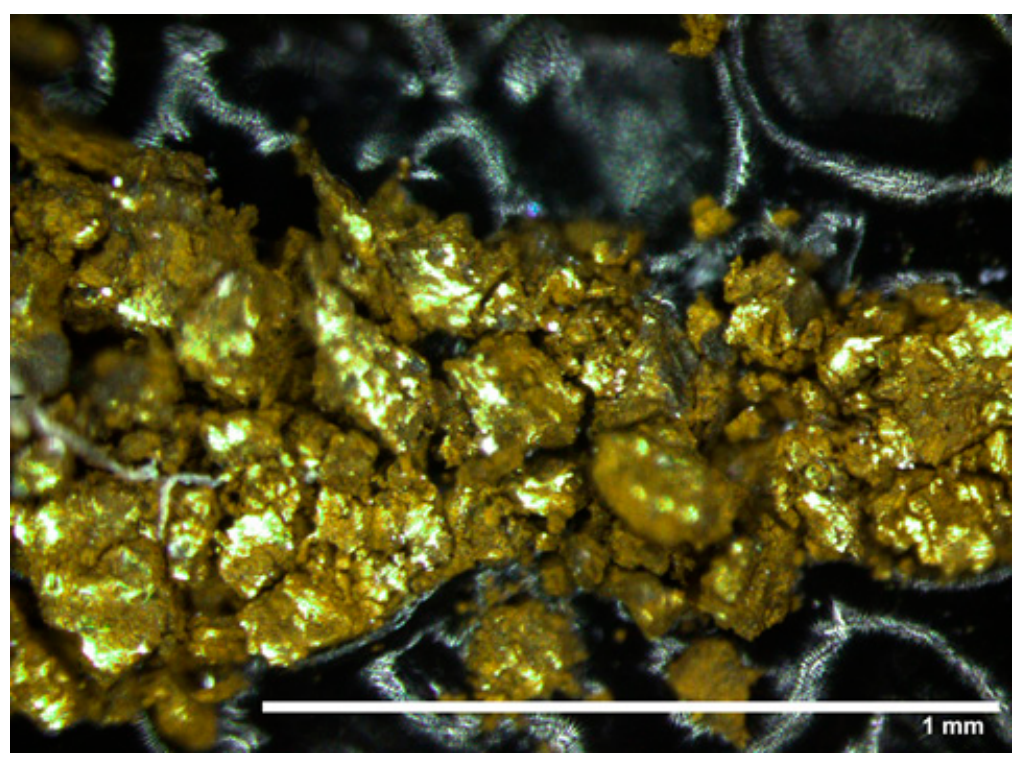

Figure 6. Zero valent gold nanoparticles obtained by sodium borohydride precipitation of the solutions resulted from the leaching with aqua regia of the gold-loaded multiwalled carbon nanotubes.

\section{Conclusions}

The experimental results indicate that it is possible to use multi-walled carbon nanotubes to remove $\mathrm{Au}(\mathrm{CN})_{2}{ }^{-}$species at alkaline $\mathrm{pH}$ values. The adsorption of this anionic species is influenced by the aqueous $\mathrm{pH}$ values, enhancing the metal adsorption as the $\mathrm{pH}$ shifted to more acidic $\mathrm{pH}$ values and the aqueous solution/adsorbent relationship decreased its value. From the experimental data, the reaction enthalpy was estimated as $-13 \mathrm{~kJ} \mathrm{~mol}^{-1}$, indicating an exothermic adsorption reaction.

From acidic chloride media, this adsorbent can also be used to remove gold(III) at $\mathrm{HCl}$ solutions, retarding the adsorption as the initial aqueous acidity is increased. In this medium, the percentage of gold(III) adsorption is near quantitative after $1 \mathrm{~h}$ contact.

Moreover, a carbon-based nanotube technology has been developed for the recovery of gold from solutions obtained from the hydrometallurgical treatment of solid wastes and its separation from common and less valuable accompanying metals in the two aqueous media. Investigations in continuous mode (columns) will be further necessary to gain final knowledge of the performance of the carbon material (no loss of the adsorptive or elution properties) under several cycles of use.

Gold is finally rendered as zero valent gold nanoparticles.

Acknowledgments: The authors wish to thank the Agency CSIC (Spain) for support.

Conflicts of Interest: The auhor declare no conflicts of interest.

\section{References}

1. Iijima, S. Helical microtubules of graphitic carbon. Nature 1991, 354, 56-58. [CrossRef]

2. Hayati, B.; Maleki, A.; Najafi, F.; Gharibi, F.; McKay, G.; Gupta, V.K.; Harikaranahalli Puttaiah, S.; Marzban, N. Heavy metal adsorption using PAMAM/CNT nanocomposite from aqueous solution in batch and continuous fixed bed system. Chem. Eng. J. 2018, 346, 258-270. [CrossRef]

3. Desouky, A.M. Remove heavy metals from groundwater using carbon nanotubes grafted with amino compound. Sep. Sci. Technol. (Philadelphia) 2018, 53, 1698-1702. [CrossRef]

4. Sebastian, M.; Mathew, B. Multiwalled carbon nanotube based ion imprinted polymer as sensor and sorbent for environmental hazardous cobalt ion. J. Macromol. Sci. Part A Pure Appl. Chem. 2018, 55, 455-465. [CrossRef] 
5. Vilardi, G.; Mpouras, T.; Dermatas, D.; Verdone, N.; Polydera, A.; Di Palma, L. Nanomaterials application for heavy metals recovery from polluted water: The combination of nano zero-valent iron and carbon nanotubes. Competitive adsorption non-linear modeling. Chemosphere 2018, 201, 716-729. [CrossRef] [PubMed]

6. Żelechowska, K.; Sobota, D.; Cieślik, B.; Prześniak-Welenc, M.; Łapiński, M.; Biernat, J.F. Bis-phosphonated carbon nanotubes: One pot synthesis and their application as efficient adsorbent of mercury. Fuller. Nanotub. Carbon Nanostruct. 2018, 26, 269-277. [CrossRef]

7. Guo, X.; Feng, Y.; Ma, L.; Yu, J.; Jing, J.; Gao, D.; Khan, A.S.; Gong, H.; Zhang, Y. Uranyl ion adsorption studies on synthesized phosphoryl functionalised MWCNTs: A mechanistic approach. J. Radioanal. Nucl. Chem. 2018, 316, 397-409. [CrossRef]

8. Xu, J.; Cao, Z.; Zhang, Y.; Yuan, Z.; Lou, Z.; Xu, X.; Wang, X. A review of functionalized carbon nanotubes and graphene for heavy metal adsorption from water: Preparation, application, and mechanism. Chemosphere 2018, 195, 351-364. [CrossRef] [PubMed]

9. Oyetade, O.A.; Nyamori, V.O.; Jonnalagadda, S.B.; Martincigh, B.S. Removal of $\mathrm{Cd}^{2+}{\text { and } \mathrm{Hg}^{2+}}_{\text {from aqueous }}$ solutions by adsorption onto nitrogen-functionalized carbon nanotubes. Desalin. Water Treat. 2018, 108, 253-267. [CrossRef]

10. Burakov, A.E.; Galunin, E.V.; Burakova, I.V.; Kucherova, A.E.; Agarwal, S.; Tkachev, A.G.; Gupta, V.K. Adsorption of heavy metals on conventional and nanostructured materials for wastewater treatment purposes: A review. Ecotoxicol. Environ. Saf. 2018, 148, 702-712. [CrossRef] [PubMed]

11. Liu, D.; Deng, S.; Maimaiti, A.; Wang, B.; Huang, J.; Wang, Y.; Yu, G. As(III) and As(V) adsorption on nanocomposite of hydrated zirconium oxide coated carbon nanotubes. J. Colloid Interface Sci. 2018, 511, 277-284. [CrossRef] [PubMed]

12. Lu, F.; Astruc, D. Nanomaterials for removal of toxic elements from water. Coord. Chem. Rev. 2018, 356, 147-164. [CrossRef]

13. Pang, S.-K.; Yung, K.-C. Prerequisites for achieving gold adsorption by multiwalled carbon nanotubes in gold recovery. Chem. Eng. Sci. 2014, 107, 58-65. [CrossRef]

14. Alguacil, F.J.; Garcia-Diaz, I.; Lopez, F.; Rodriguez, O. Removal of Cr(VI) and Au(III) from aqueous streams by the use of carbon nanoadsorption technology. Desalin. Water Treat. 2017, 63, 351-356. [CrossRef]

15. Alguacil, F.J.; Lopez, F.A.; Rodriguez, O.; Martinez-Ramirez, S.; Garcia-Diaz, I. Sorption of indium(III) onto carbon nanotubes. Ecotoxicol. Environ. Saf. 2016, 130, 81-86. [CrossRef] [PubMed]

16. Alguacil, F.J.; Caravaca, C. Synergistic extraction of gold(I) cyanide with the primary amine Primene JMT and the phosphine oxide Cyanex 921. Hydrometallurgy 1996, 42, 197-208. [CrossRef]

17. Marsden, J.O.; House, C.I. Solution purification and concentration. In The Chemistry of Gold Extraction; SME Publication: Littleton, CO, USA, 2006.

18. Ho, Y.S.; McKay, G. Pseudo-second order model for sorption processes. Proc. Biochem. 1999, 34, 451-465. [CrossRef]

19. Chen, L.; Yu, S.; Liu, B.; Zuo, L. Removal of radiocobalt from aqueous solution by different sized carbon nanotubes. J. Radioanal. Nucl. Chem. 2012, 292, 785-791. [CrossRef]

20. Kupai, J.; Razali, M.; Buyuktiryaki, S.; Kecilic, R.; Szekely, G. Long-term stability and reusability of molecularly imprinted polymers. Polym. Chem. 2017, 8, 666-673. [CrossRef] [PubMed]

21. Rohanifar, A.; Rodriguez, L.B.; Devasurendra, A.M.; Alipourasiabi, N.; Anderson, J.L.; Kirchhoff, J.R. Solid-phase microextraction of heavy metals in natural water with a polypyrrole/carbon nanotube/1, 10-phenanthroline composite sorbent material. Talanta 2018, 188, 570-577. [CrossRef] [PubMed]

22. Azamat, J.; Hazizadeh, B. Removal of Cd(II) from water using carbon, boron nitride and silicon carbide nanotubes. Membr. Water Treat. 2018, 9, 63-68. [CrossRef]

23. Alguacil, F.J.; Adeva, P.; Alonso, M. Processing of residual gold(III) solutions via ion exchange. Gold Bull. 2005, 38, 9-13. [CrossRef]

(C) 2018 by the author. Licensee MDPI, Basel, Switzerland. This article is an open access article distributed under the terms and conditions of the Creative Commons Attribution (CC BY) license (http://creativecommons.org/licenses/by/4.0/). 